\title{
Reparación simbólica a Víctimas de desaparición forzada a través de la imagen fotográfica
}

\author{
Jose Morales
}

Asesora: Beatriz Enciso

Maestría en Comunicación, Desarrollo y Cambio Social 
Línea de Investigación: Comunicación, derechos y memoria.

Modalidad: De profundización.

\section{Pregunta:}

¿De qué forma la fotográfica, como forma de reparación simbólica, aporta al proceso de dignificación, reconocimiento y visibilización de las víctimas de desaparición forzada?

\section{Objetivo general:}

Contribuir, desde la reflexión crítica, a la discusión sobre el uso de la imagen fotográfica como forma de reparación simbólica, que permite generar espacios de participación, reconocimiento, dignificación y re-construcción de la memoria respecto de las víctimas de desaparición forzada. 


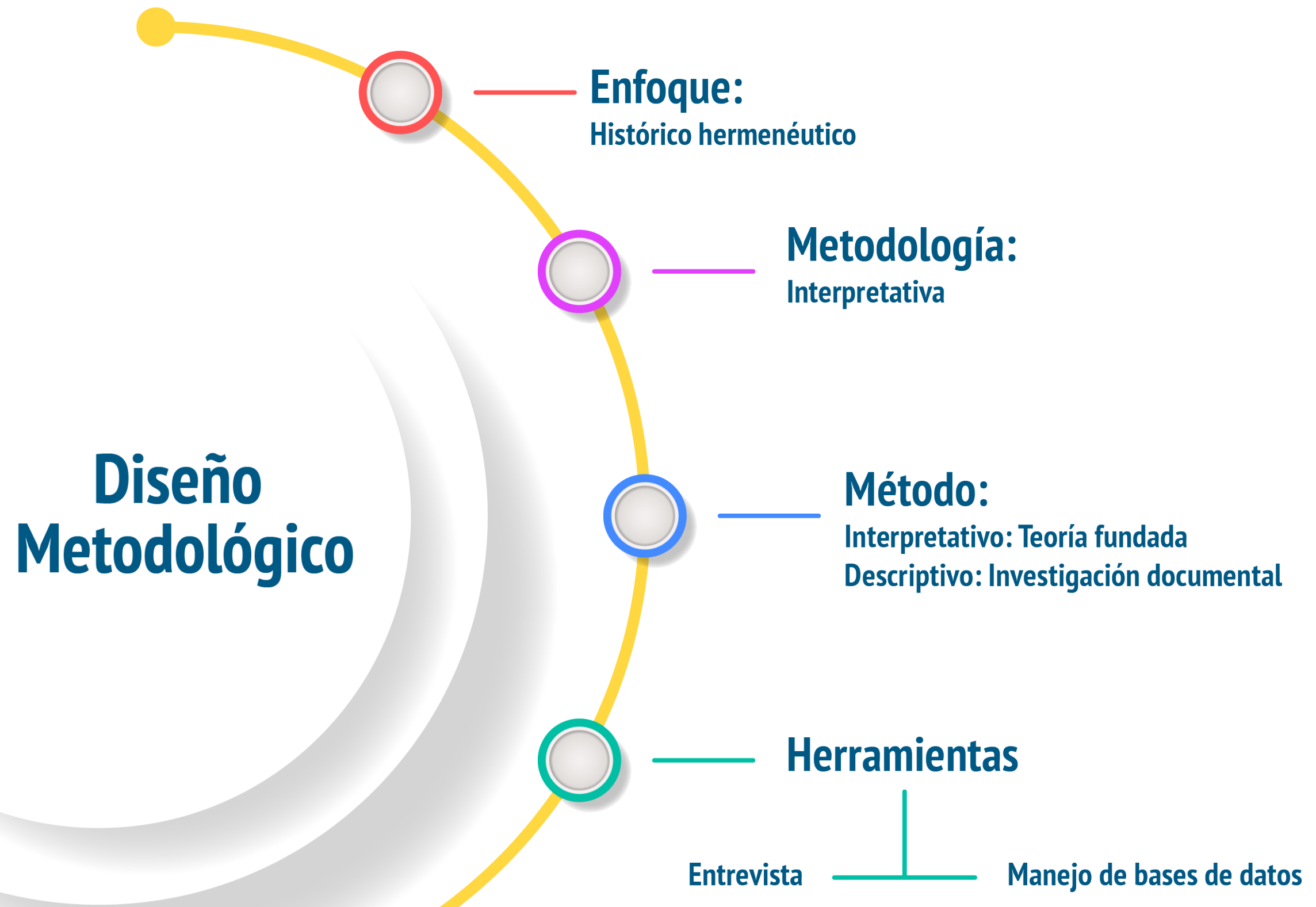




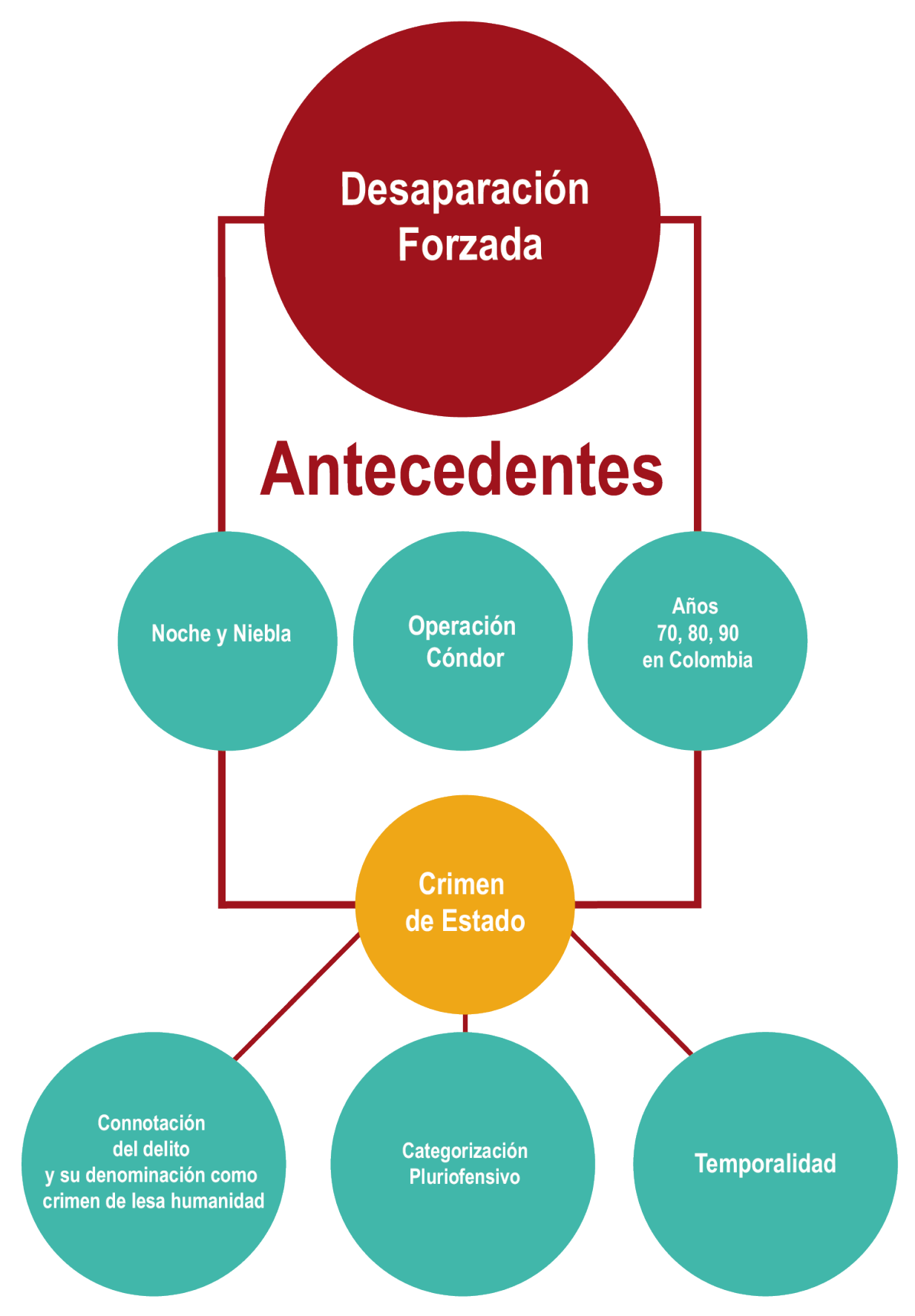




\section{Justicia}

\section{Reparación Integral}

Adecuada - Diferenciada - Transformadora - Efectiva

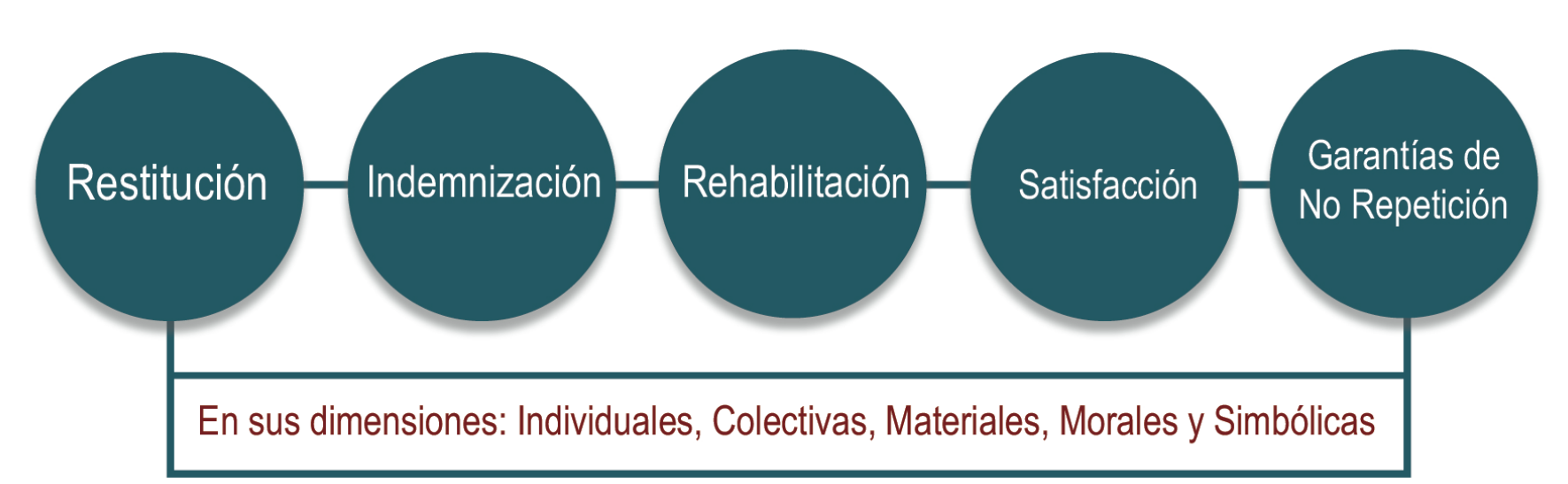

Dimensión Simbólica 


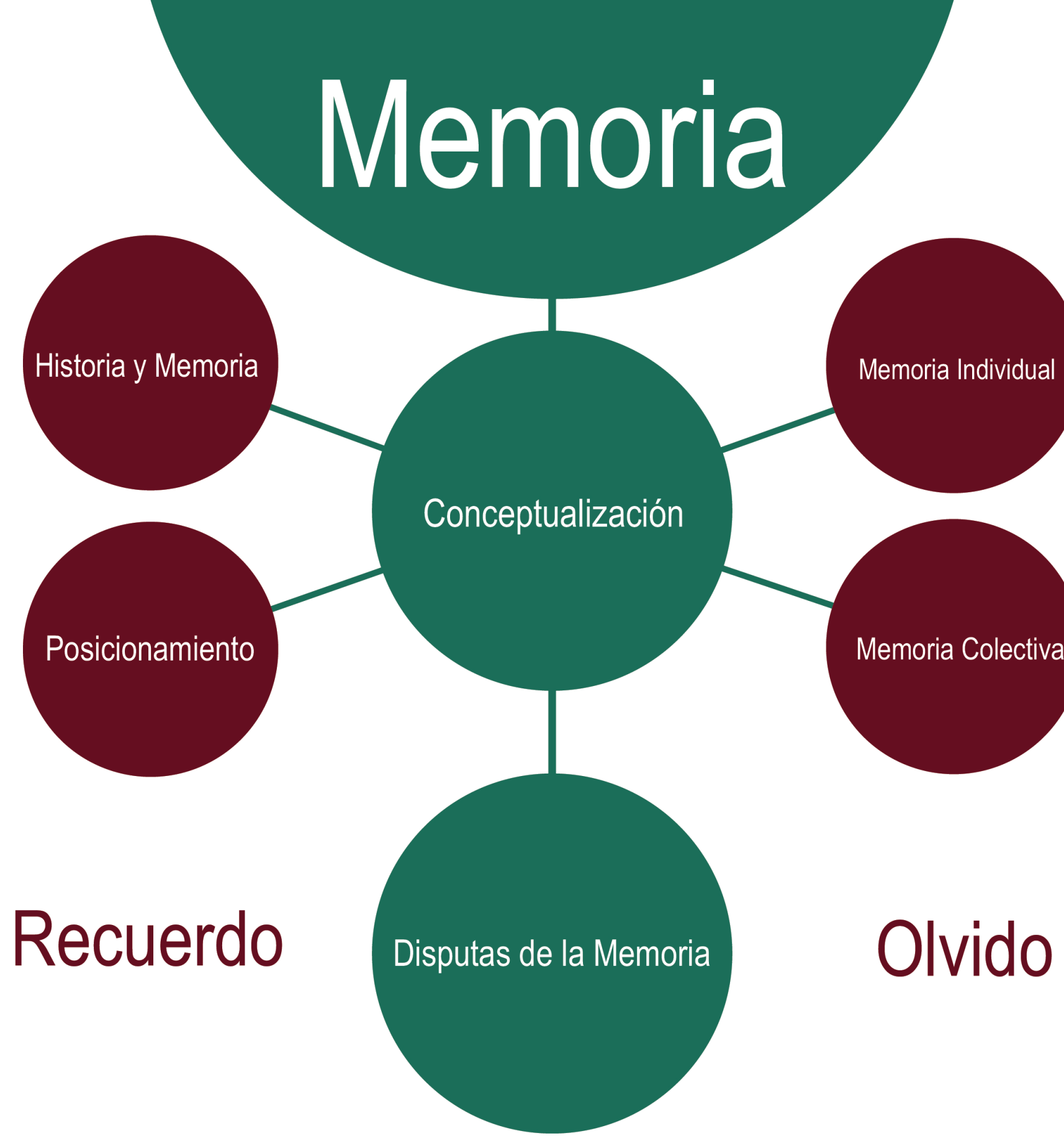




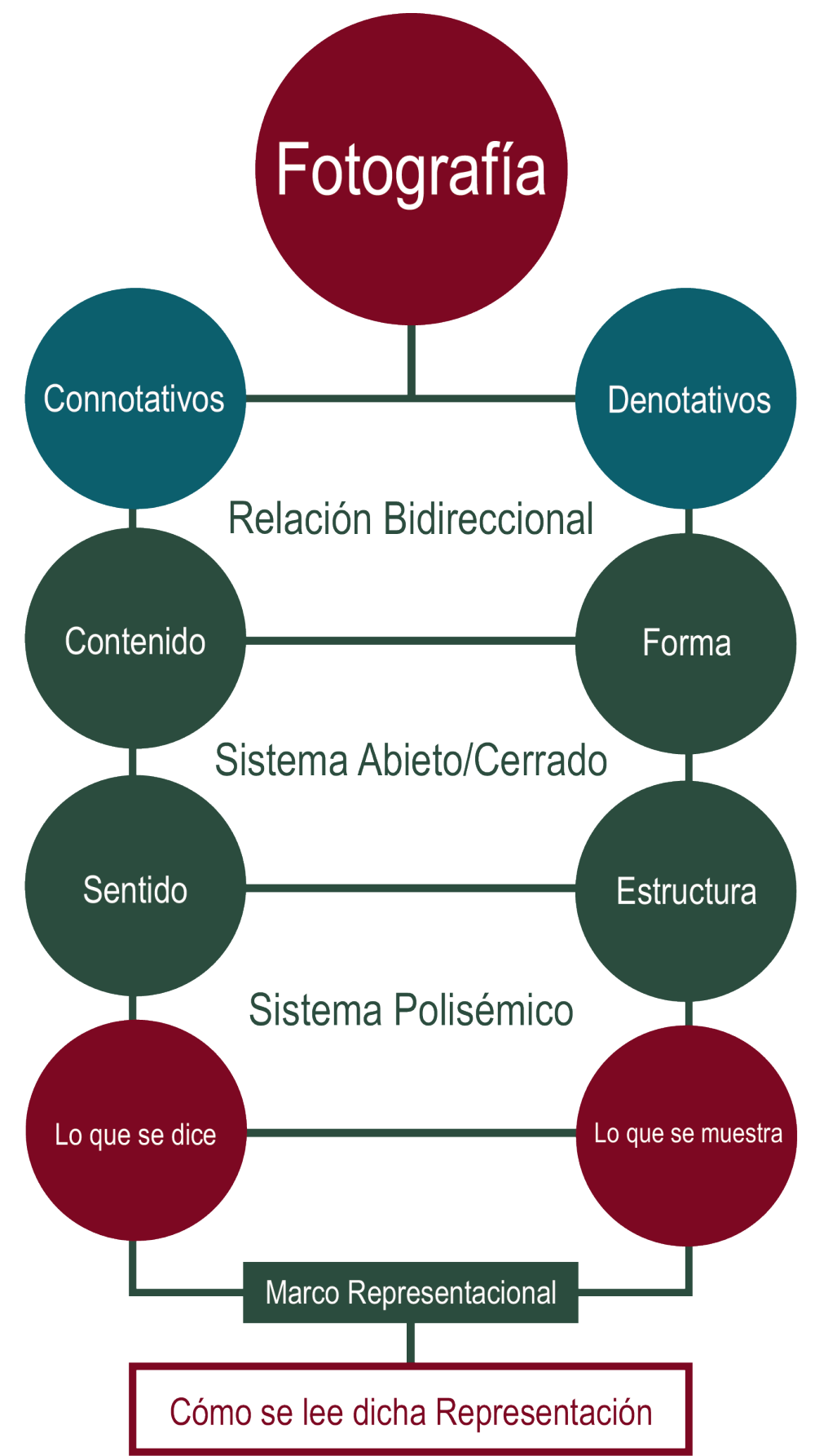




\section{Conclusiones}

El trabajo de reparación simbólica, al igual que el resto de las formas de reparación, requiere de una labor inter y multidisciplinar. No obstante, a esta se le suma una dimensión estética compleja, que en muchas de las otras modalidades de reparación no es contemplada. Este componente estético puede ser interpretado como una forma particular de subjetivación en donde las víctimas se ubican y reconocen de múltiples formas. 
Por otro lado, queda claro que la personalización de la reparación con enfoque diferencial, demanda atención conjunta de las condiciones particulares de la situación acaecida, dado que, si no se evalúan aquellas con total claridad, podrían generarse consecuencias adversas para la persona o personas involucradas en el proceso reparatorio. La mejor de las formas de llevar a buen término todo el proceso y de brindar aportaciones realmente representativas a las víctimas, es la participación.

\section{Empoderamiento y agenciamiento}


El uso de la fotografía, como plataforma de visibilización de las historias de personas que han tenido que lidiar con los horrores de la guerra, debe ser entendido como una poderosa alternativa que permite generar procesos de reparación. Quizás sea este uno de los modos más adecuados de llevar estos mensajes a públicos más diversos. 
La fotografía, como unidad simbólica y estética de información, puede considerarse una manera efectiva de enunciar a través de la mostración gráfica. Dado que, en algunas situaciones concernientes a desapariciones, existen dificultades al momento de verbalizar cierta información. Lo mejor en estos casos es buscar maneras alternas de narrar y resignificar sentidos.

Otra forma de contar las historias y de narrar el conflicto 
En tanto se logre una resemantización de lo acaecido, el camino hacia la superación del hecho traumático estará parcialmente abierto. Como es de inferir, esto requiere de otras acciones que vayan reforzando la labor que desde lo simbólico se realice. Que el Estado -y de otros actores- asuman sus responsabilidades frente a todo el otro espectro que concierne a la reparación integral, tiene aquí un gran sentido, pues no es posible trabajar por una reparación sin verdad, justica y garantías de no repetición. 
La fotografía como documento social, contribuye de forma directa a la formación de una memoria gráfica del conflicto. En tanto se pueda llegar a ocupar, con estos archivos de la memoria, espacios de participación y visibilización con alcances más amplios, se construirá, de forma colectiva, un relato más diversificado y consciente sobre el fenómeno de la desaparición forzada. 
Por último, para este trabajo fue de gran importancia preguntarse por el papel de la imagen fotográfica como forma mediante la cual se pueden adelantar procesos de reparación simbólica con víctimas de desaparición forzada. Pues a partir de ello, se identificó un amplio espectro de tenciones entorno a las relaciones entre la comunicación, el arte, la memoria, la política y la sociedad. En dicho escenario, es reconocible que una postura crítica y reflexiva frente a este flagelo es imperativa. Además de una amplia visión al momento de abordarlo como tema de investigación. 


\section{Algunos de los aportes a la línea de investigación}

\section{Línea de investigación: Comunicación, derechos y memoria}

- Genera una discusión entorno al uso de la fotografía como forma estética/material que puede llegar a contribuir en procesos de reparación simbólica.

- Pone en evidencia la necesidad de pensar otras formas y otros lugares de enunciación (Narrativas del conflicto y construcción de la memoria gráfica).

- Deja la puerta abierta para que se empiece a cuestionar el actuar de algunos particulares y organizaciones -estatales o civiles- frente al trato que se le da a las historias relacionadas con desapariciones forzadas.

- Contribuye, como propuesta teórico/crítica, al espectro de conocimiento frente al tema de la desaparción forzada de personas. Ello desde una perspectiva conpleja. 


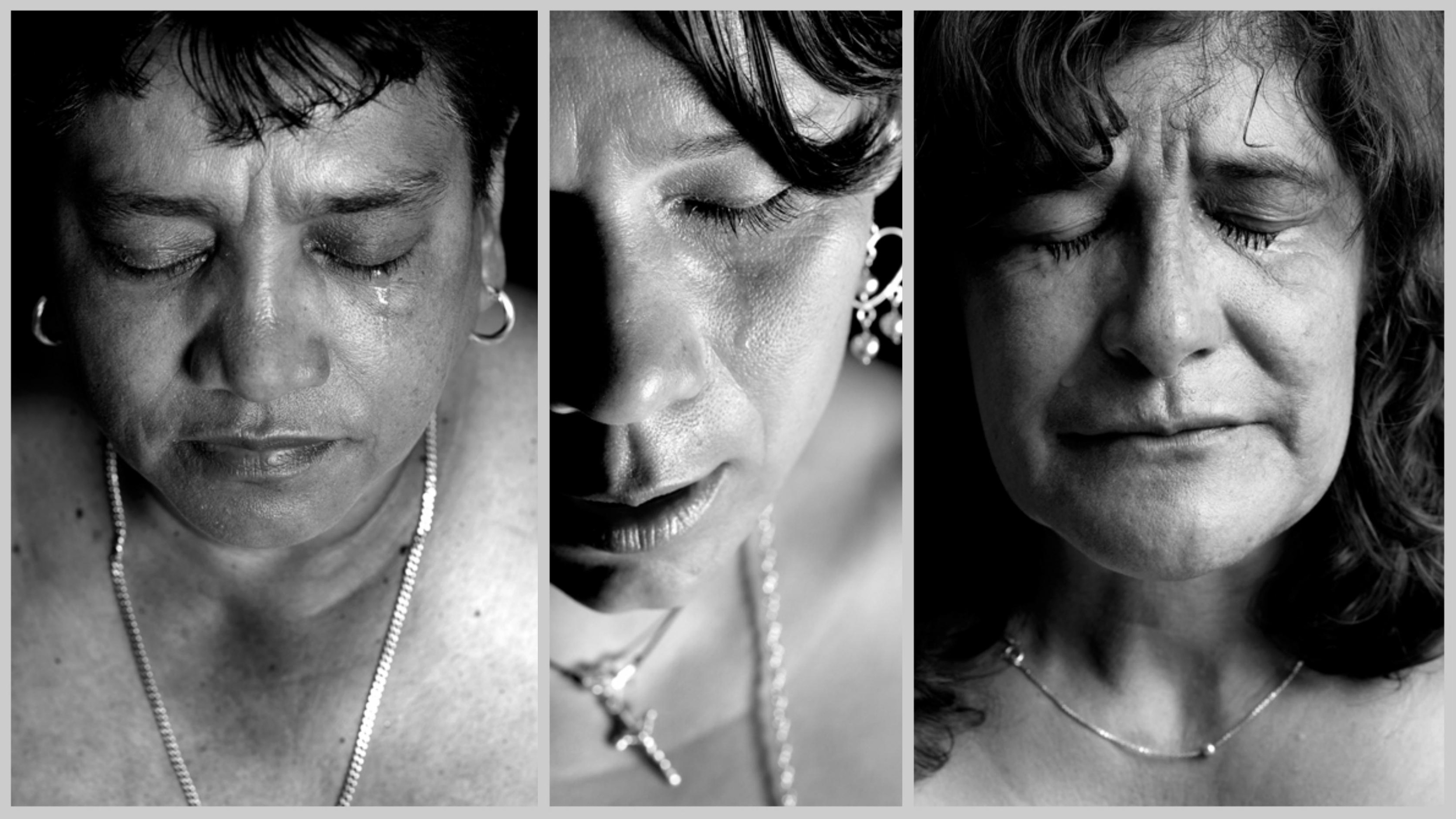




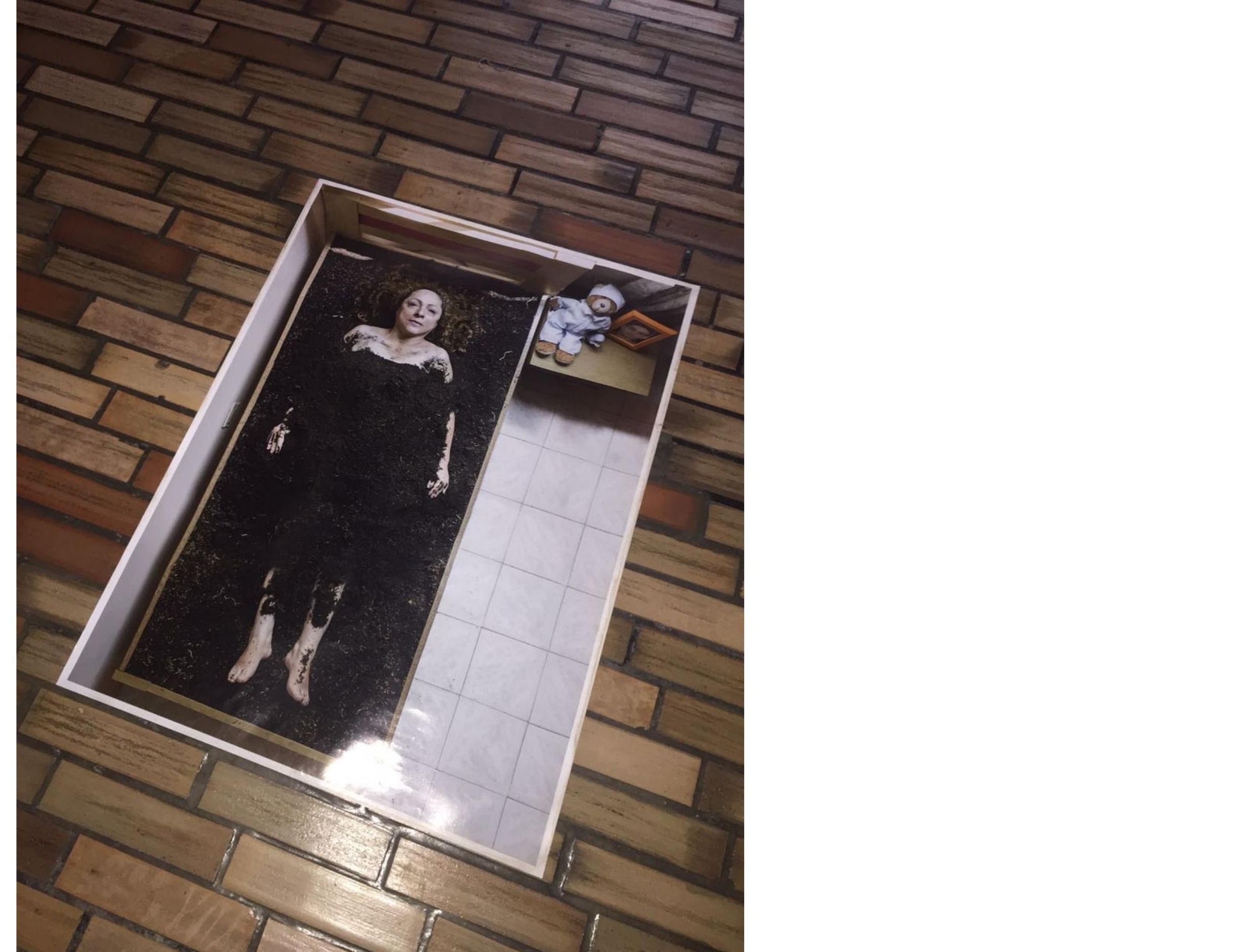




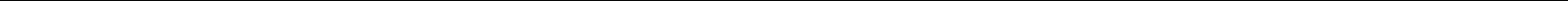



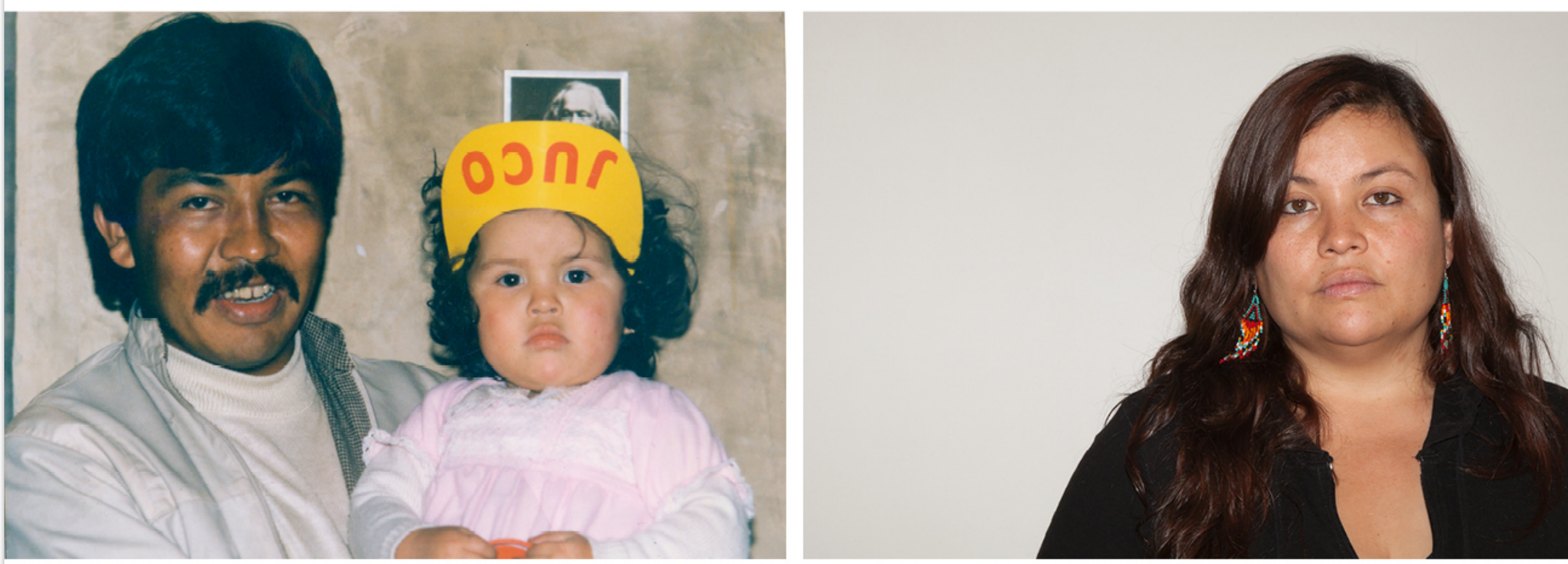


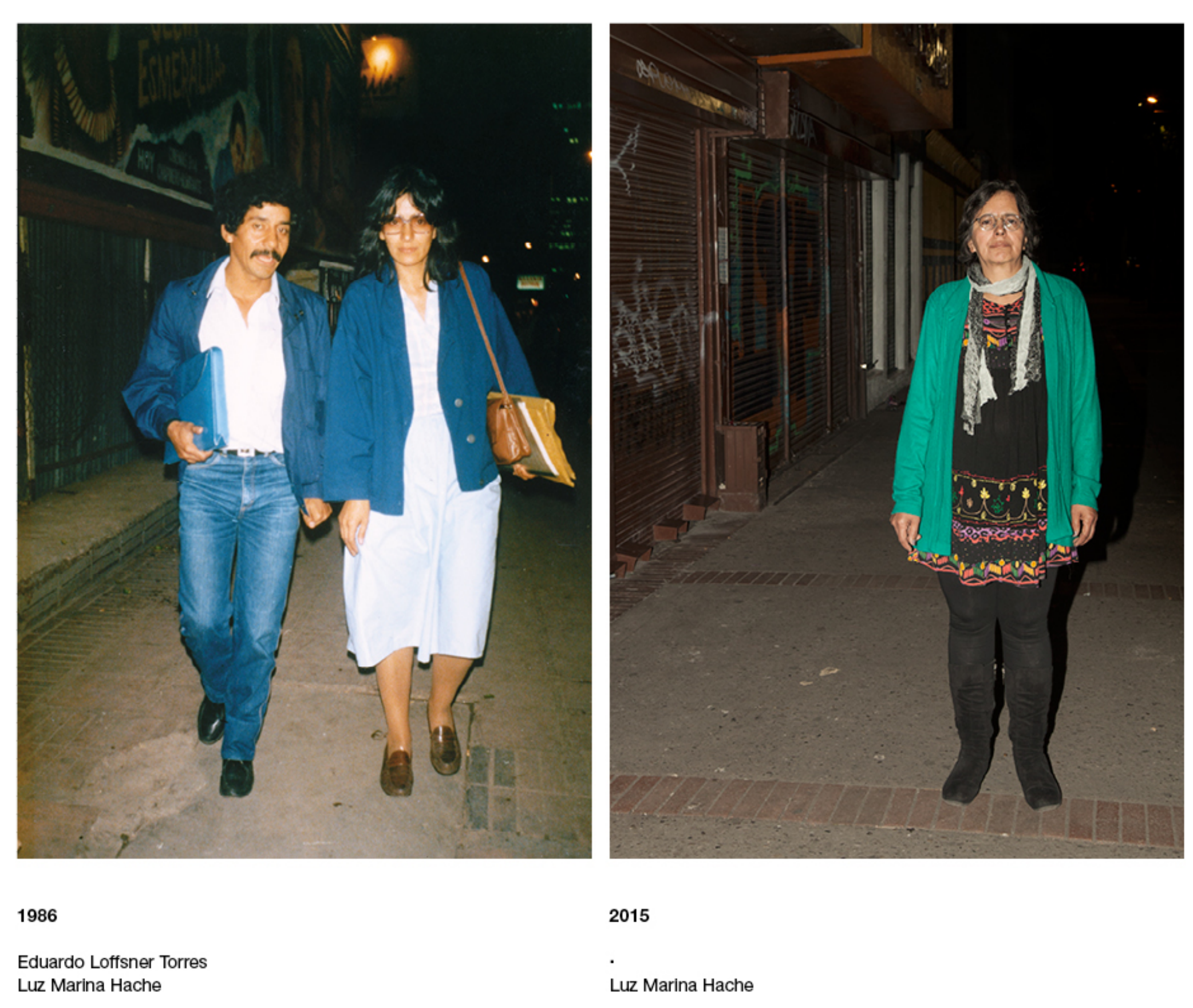




\section{Bibliografía}

- Aladro Vico, Eva. (2010). La estructura de los símbolos: perspectivas de la comunicación. Vol. 3, № 2, 2010. PP. 134-147. Universidad de la Frontera. TemucoChile.

O Barthes, Roland. (1980). La cámara lúcida: nota sobre la fotografía, 3a Ed. Editorial Paidós Ibérica S.A. España.

O Barthes, Roland. (1986). Lo obvio y lo obtuso: imágenes, gestos, voces. Ediciones Paidós lbérica, S. A. España.

O Barthes, Roland. (1993). La aventura semiológica. Ediciones Paidós Ibérica, S. A. España.

O Benjamin, Walter. (2001). Para una crítica de la violencia y otros ensayos. Ed. Alfaguara, S.A. España.

O Benjamin, Walter. (2005). Sobre la fotografía. Guada Impresores. España. 
O Beristain, Carlos Martín. (2010). Diálogos sobre la reparación: qué reparar en los casos de violaciones de Derechos Humanos. Instituto Internacional de Derechos Humanos. Serie Justicia y Derechos Humanos, Neoconstitucionalismo y Sociedad. M\&RG. San José-Costa Rica.

O Blair Trujillo, Elsa. (2002). Memoria y narrativa: la puesta del dolor en la escena pública. Revista de Estudios Políticos No. 21. Medellín, junio/diciembre 2002, Pág. 9-28. Colombia. Este artículo surge de la investigación titulada Olvido, Silencio y Memoria: Las heridas abiertas de la (s) violencia(s), realizada por el grupo de investigación Cultura, Violencia y Territorio del Instituto de Estudios Regionales (INER) de la Universidad de AntioquiaColombia.

O Calloni, Stella. (2016). Operación cóndor: pacto criminal. Fundación Editorial: El perro y la rana. Venezuela.

O Cardona, Álvaro. (20016). Padre, hijo y espíritu armado. Exposición fotográfica. Colombia. 
O Centro Nacional de Memoria Histórica. (2013). Huellas y rostros de la desaparición forzada 1970 - 2010, Tomo II. Informe del Centro Nacional de Memoria Histórica. Bogotá-Colombia.

O Centro Nacional de Memoria Histórica. (2014). Balance de la acción del Estado colombiano frente a la desaparición forzada de personas, Tomo IV. Informe del Centro Nacional de Memoria Histórica. Bogotá-Colombia.

O Centro Nacional de Memoria Histórica. (2014). Entre la incertidumbre y el dolor: impactos psicosociales de la desaparición forzada, Tomo III. Informe del Centro Nacional de Memoria Histórica. Bogotá-Colombia.

O Centro Nacional de Memoria Histórica. (2014). Normas y dimensiones de la desaparición forzada en Colombia, Tomo I. Informe del Centro Nacional de Memoria Histórica. BogotáColombia.

O Centro Nacional de Memoria Histórica. (2016). Hasta encontrarlos: el drama de la desaparición forzada en Colombia. Informe del Centro Nacional de Memoria Histórica. Bogotá-Colombia. 
O Código Penal Colombiano. (Ley 599 de 2000). Delitos contra la libertad individual y otras garantías. Capítulo 1. Artículo 165. Desaparición Forzada.

O Comisión Colombiana de Juristas. (2007). Principios internacionales sobre impunidad y reparación. Compilación de documentos de la Organización de las Naciones Unidas (ONU). Ed. Gráficas Editores Ltda. Bogotá-Colombia.

O Convención Interamericana sobre Desaparición Forzada de Personas (1994). Adoptada en el vigésimo cuarto período ordinario de sesiones de la Asamblea General de la OEA.

- Declaración Sobre la Protección de Todas las Personas Contra las Desapariciones Forzadas. Adoptada por: Asamblea General de la ONU. Resolución 47/133, 18 de diciembre de 1992. 
O Diettes, Erika. (2008). Río abajo. Exposición fotográfica. Colombia.

O Diettes, Erika. (2011). Sudarios. Exposición fotográfica. Colombia.

O Druliolle, Vincent. (2015). Políticas de la memoria. Revista en Cultura de la Legalidad. No. 7, septiembre 2014-febrero 2015, PP. 198-207. España.

O Estatuto de Roma. Corte Penal Internacional. Distribuido como documento A/CONF.183/9, de 17 de julio de 1998, enmendado por los Procès Verbaux de 10 de noviembre de 1998, 12 de julio de 1999, 30 de noviembre de 1999, 8 de mayo de 2000, 17 de enero de 2001 y 16 de enero de 2002.

O Ewing, A. William. (2008). El rostro humano: el nuevo retrato fotográfico. Art. Blume, S.L.

O Fontcuberta, Joan. (1990). Fotografía: conceptos y procedimientos. Una propuesta metodológica. Ediciones Gustavo Gili.

O Fontcuberta, Joan. (1997). El beso de judas: fotografía y verdad. Editorial Gustavo Gili, S.A. España.

O Fontcuberta, Joan. (2003). Estética fotográfica: una selección de textos. Editorial Gustavo Gili, S.A. España.

O Freund, Gisèle. (1993). La fotografía como documento social. Editorial Gustavo Gili, SL, Barcelona-España. 
O Germano, Gustavo. (2006). Ausencias. Exposición fotográfica. Argentina.

O GMH ¡Basta ya! Colombia: memorias de guerra y dignidad. (2013). Informe general Grupo de Memoria Histórica. Centro Nacional de Menoría Histórica. Imprenta Nacional. BogotáColombia.

O González Caballero, David Eduardo. (2016). Emociones y cultura política. Análisis de las galerías de la memoria presentadas por el Capítulo Bogotá del Movimiento Nacional de Víctimas de Crímenes de Estado (Movice). Estudios Políticos, 48, Instituto de Estudios Políticos, Universidad de Antioquia, pp. 157-178. DOI: 10.17533/udea.espo.n48a09

O Guilis, Graciela. (2007). La reparación: acto jurídico y simbólico. Departamento de Entidades de la Sociedad Civil del Instituto Interamericano de Derechos Humanos.

O Halbwachs, Maurice. (2004). La memoria colectiva. Ed. Prensas Universitarias de Zaragoza. Zaragoza-España.

O Hechavarria, Juan Manuel. (2013). Requiem N.N. Colombia.

O Huhle, Rainer (2014). Noche y niebla: mito y significado. Capítulo extraído del libro Desapariciones Forzadas de Niños en Europa y Latinoamérica. Del Convenio de la ONU a las Búsquedas a Través del ADN. Ediciones de la Universidad de Barcelona-España.

O Jelin, Elizabeth. (2002). Los trabajos de la memoria. Colección Memorias de la Represión Ed. Siglo Veintiuno Argentina. 
O Jonathan "Jonás" Moller. (2016). El pasado es hoy: memorias del pasado reciente del Perú 1980 - 2014. Exposición fotográfica. Perú.

O Ley de Victimas. 1448 de junio 10 de 2011. Por medio de la cual se dictan medidas de atención, asistencia y reparación integral a las víctimas del conflicto armado interno y se dictan otras disposiciones.

O Maddow, Ben. (1977). Face: a narrative history of the portrait in photography. New York Graphic Society.

- Martínez Quintero, Felipe. (2013). Las prácticas artísticas en la construcción de memoria sobre la violencia y el conflicto. Eleuthera, Vol. 9, julio-diciembre. pp. 39-58.

O Mukařovský, Jan. (1997). Escritos de estética y semiótica del arte. Colección Comunicación Visual. Editorial Gustavo Gili, S.A. Barcelona - España.

O Natalia Fortuna (2007). Fotografía y memoria: una aproximación a partir de los escritos de Walter Benjamin, Roland Barthes y Gilles Deleuze. VII Jornadas de Sociología. Facultad de Ciencias Sociales, Universidad de Buenos Aires, Buenos Aires-Argentina. 
O Pantoja Chávez, Antonio. (2008). La sociedad de la imagen: la fotografía como recurso para la memoria. I Encuentro de Jóvenes Investigadores en Historia Contemporánea de la Asociación de Historia Contemporánea. Zaragoza-España.

O Patiño Yepes, Álvaro Alfonso. (2010). Las reparaciones simbólicas en escenarios de justicia transicional. Artículo que se desprende del proyecto de investigación titulado: Construcción de una propuesta de reparación integral a víctimas de violaciones a Derechos Humanos a partir de la jurisprudencia de la Corte Interamericana de Derechos Humanos. Revista Latinoamericana de Derechos Humanos Vol. 21 (2): PP. 51-61, julio-diciembre, 2010. Colombia.

O Pérez, Claudio. (2007). El amor ante el olvido. Exposición fotográfica. Chile.

O Ramírez Molano, Constanza (2013). Doble oficio por la entrega digna. Colombia.

O Restrepo Zapata, Camilo. (2002). La foto de identidad: fragmentos para una estética. Fondo Editorial Universidad EAFIT. Medellín-Colombia.

O Ricoeur, Paul. (2000). La memoria, la historia, el olvido. Fondo de Cultura Económica de Argentina, S.A.

O Rubiano Pinilla, Elkin. (2012). Arte, memoria y participación: "¿dónde están los desaparecidos?". Hallazgos No. 23. Universidad Santo Tomas, pp. 31-48. Bogotá-Colombia.

O Saavedra, Carlos. (2014). Madres terra. Exposición fotográfica. Colombia.

O Sontag, Susan. (2008). Sobre la fotografía. Random House Mondadori. S. A. Barcelona- España. 
O Todorov, Tzvetan. (2000). Los abusos de la memoria. Editorial Paidós Ibérica S.A, SAICF. Argentina.

O Trigésimo Tercer Periodo de Sesiones, Asamblea General de la ONU en su $90^{\circ}$ Sesión Plenaria, del 20 de diciembre de 1978. Resolución 33/173, Personas Desaparecidas.

O Vera Piñeros, Diego. (2008). Desarrollo internacional de un concepto de reparación a las víctimas de violaciones a los Derechos Humanos e infracciones al Derecho Internacional Humanitario: complementos a la perspectiva de la ONU. Ciencias Políticas y Relaciones Internacionales, Vol. 13, No 2. PP. 737-773, Julio-diciembre. Pontificia Universidad Javeriana. Bogotá-Colombia.

O Zout, Helen (2015). Huellas de Desapariciones. Argentina. 